
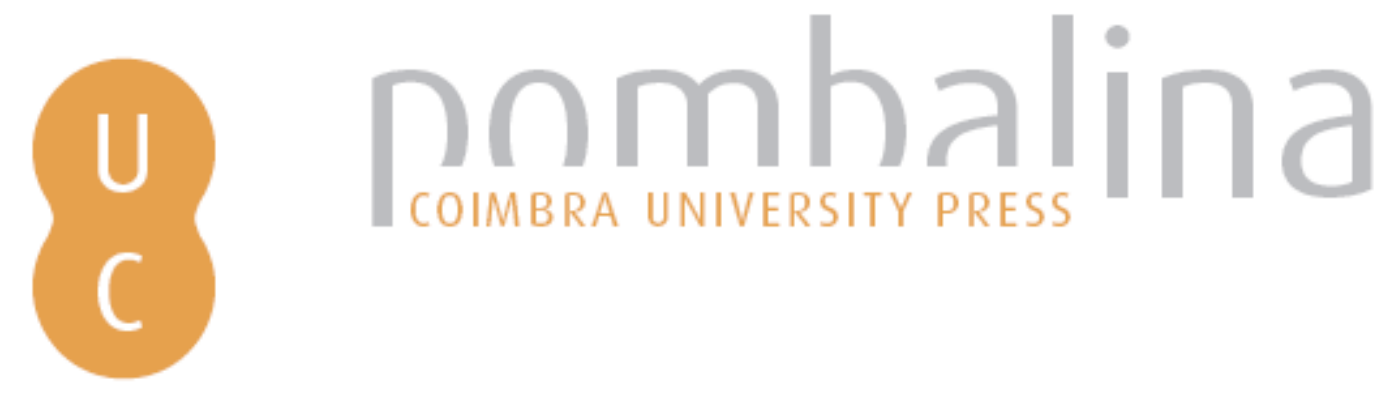

\title{
Identificação de depósitos do tsunami de 1755 e sua comparação com cenários de tempestade: estuário da Boca do Rio
}
Autor(es):
Simões, Nuno; Veiga-Pires, Cristina
Publicado por: Imprensa da Universidade de Coimbra
URL
persistente:
URI:http://hdl.handle.net/10316.2/38298
DOI:
DOI:http://dx.doi.org/10.14195/9789892610993_11
Accessed : $\quad$ 26-Apr-2023 02:19:09

A navegação consulta e descarregamento dos títulos inseridos nas Bibliotecas Digitais UC Digitalis, UC Pombalina e UC Impactum, pressupõem a aceitação plena e sem reservas dos Termos e Condições de Uso destas Bibliotecas Digitais, disponíveis em https://digitalis.uc.pt/pt-pt/termos.

Conforme exposto nos referidos Termos e Condições de Uso, o descarregamento de títulos de acesso restrito requer uma licença válida de autorização devendo o utilizador aceder ao(s) documento(s) a partir de um endereço de IP da instituição detentora da supramencionada licença.

Ao utilizador é apenas permitido o descarregamento para uso pessoal, pelo que o emprego do(s) título(s) descarregado(s) para outro fim, designadamente comercial, carece de autorização do respetivo autor ou editor da obra.

Na medida em que todas as obras da UC Digitalis se encontram protegidas pelo Código do Direito de Autor e Direitos Conexos e demais legislação aplicável, toda a cópia, parcial ou total, deste documento, nos casos em que é legalmente admitida, deverá conter ou fazer-se acompanhar por este aviso.

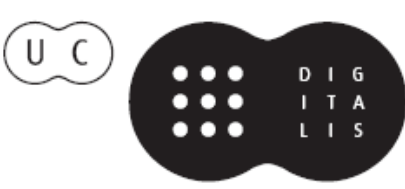




\section{TERRAMOTO DE \\ LISBOA DE 1755}

\section{O QUE APRENDEMOS \\ 260 ANOS DEPOIS?}

LUCIANO LOURENÇO

ÂNGELA SANTOS

(COORDS.)

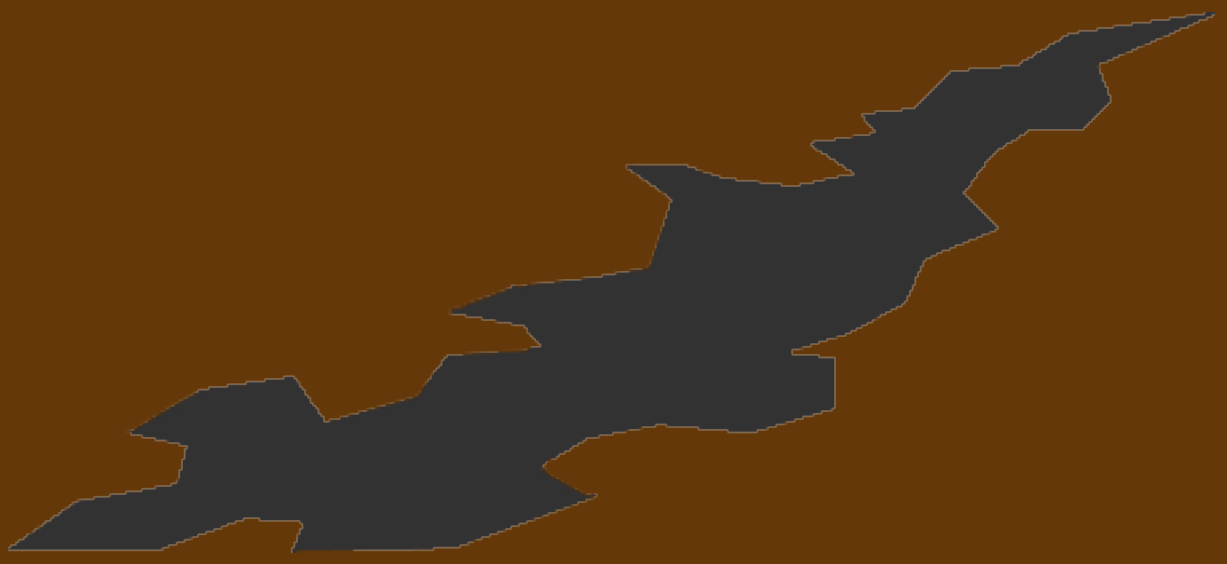

IMPRENSA DA UNIVERSIDADE

DE COIMBRA

COIMBRA

UNIVERSITY

PRESS 


\title{
IDENTIFICAÇÁO DE DEPÓSITOS DO TSUNAMI DE 1755 E SUA COMPARAÇÁO COM CENÁRIOS DE TEMPESTADE- ESTUÁRIO DA BOCA DO RIO IDENTIFICATION OF THE 1755 LISBON TSUNAMI DEPOSITS AND THEIR COMPARISON WITH STORM SCENARIOS AT BOCA DO RIO ESTUARY
}

\begin{abstract}
Nuno Simóes Centro de Investigação Marinha e Ambiental, Universidade do Algarve nunosimoes58@gmail.com

Cristina Veiga-Pires Centro de Investigaçáo Marinha e Ambiental e FCT, Universidade do Algarve cvpires@ualg.pt
\end{abstract}

Sumário: Os tsunamis apresentam um enorme potencial destruidor, o que faz com que este tema seja bastante importante na investigação. Desta forma, com o presente trabalho, pretende-se enquadrar a caracterização do depósito de tsunami que está presente no Estuário da Boca do Rio e que foi gerado pelo terramoto de 1755. Esta caracterização foi realizada através de técnicas de colorimetria, granulometria e magnetismo. Por fim, é realizada uma comparação entre o cenário deste depósito com um cenário de ondas de tempestade, provenientes da tempestade Hércules, que assolaram este estuário entre 5 e 7 de Janeiro de 2014.

Palavras-chave: Terramoto 1755 , depósitos de tsunami, estuário, ondas de tempestade, sedimentos 


\begin{abstract}
The Tsunamis have enormous destructive potential, so the research about this subject is very important. Accordingly, the present work aims to characterize the tsunami deposit that is present at the Boca do Rio Estuary and was generated by the 1755 earthquake. This characterization is performed by colorimetric techniques, grain size and magnetism. Finally, we compare the scenario of this sedimentary deposition to the one related to storm waves, from Storm Hercules, that reached this estuary between $5^{\text {th }}$ and $7^{\text {th }}$ of January 2014.
\end{abstract}

Keywords: 1755 earthquake, tsunami deposit, estuary, storm waves, sediments

\title{
Introduçáo
}

Ao longo dos anos, Portugal tem sido afetado por diversos sismos de magnitude moderada a forte, que muitas vezes resultam em danos consideráveis. A maioria dos sismos de maior intensidade tiveram a sua origem nas zonas interplacas (zonas de sismicidade elevada), mais concretamente no oceano, pois Portugal está próximo da fronteira entre a placa Africana e Euro-Asiática. Um exemplo destes sismos foi o violento terramoto de 1755 que, por si só, fez estragos desde Lisboa ao Algarve e, ainda, foi acompanhado por um maremoto (Tsunami) que submergiu e destruiu muitas zonas costeiras. Os tsunamis, apesar de pouco frequentes, têm um enorme potencial destruidor comparativamente a outros eventos naturais, o que os torna num importante tema de investigação. Contudo, foi apenas a partir do tsunami de Sumatra, em 2004, que a investigação sobre impactos de tsunami tem evoluído.

Os diversos impactos devidos aos tsunamis variam desde os danos materiais aos danos humanos e económicos, pois estes eventos originam uma inundação efémera mas de forte energia, que produz erosão, sedimentação e retrabalho de sedimentos costeiros, sendo estes processos suscetíveis de preservação e de reconhecimento no registo sedimentar. A identificação de tsunamis nos registos sedimentares, ou identificação de paleotsunamis, é bastante importante na 
compreensão dos impactos destes eventos e na delimitação da sua propagação. No entanto, reconstruir e compreender paleotsunamis é ainda difícil, pois é complicado distinguir estes depósitos de um de tempestade, devido a ambos apresentarem mecanismos deposicionais semelhantes (Pratt, 2002; Shanmugam, 2006; Dawson e Stewart, 2007; Morton et al., 2007; Tapin, 2007). Apesar destas limitaçóes, existem depósitos de tsunami bem descritos na literatura (Luque et al., 2001; Dawson e Stewart, 2007). Um exemplo deste tipo de depósitos é o proveniente do tsunami do terramoto de Lisboa de 1755, que se encontra no Estuário da Boca do Rio, situado na costa Sul do Algarve (Portugal), e que está datado por termoluminescência e bem descrito apresentando ótimas condiçóes de preservação do registo sedimentológico (Font et al., 2010; ; Font et al., 2012; Simóes, 2012). Numa primeira fase, para interpretar um depósito de tsunami é essencial estudar modelos de inundaçáo aplicados à zona do evento, pois estes modelos fornecem parâmetros físicos (inundação, velocidade e correntes) que podem estar ligados a mecanismos deposicionais (erosão, transporte e deposição) da onda de tsunami. Numa segunda fase, os sedimentos relativos aos depósitos de tsunamis podem dar informaçóes, indiretamente sobre parâmetros físicos e diretamente sobre os mecanismos deposicionais, quando analisados com técnicas de colorimetria, granulometria e magnetismo (Simões, 2012; Font et al., 2012; Font et al., 2013).

Como referido anteriormente, é ainda díficil distinguir estes depósitos dos depósitos de tempestade, pois ambos apresentam mecanismos deposicionais semelhantes. Desta forma, o presente estudo tem como objetivo, realizar uma comparação entre um depósito de tsunami que se encontra localizado na Boca do Rio (Algarve, Portugal) com os registos sedimentológicos e os impactos das ondas de tempestade (storm waves) originadas pela tempestade Hércules. Esta tempestade ocorreu devido à existência de uma prevalência de ar polar no continente norte-americano, em dezembro de 2013 e Janeiro de 2014, sendo que temperaturas muito negativas permaneceram durante 4-6 semanas no Canadá e na metade leste dos EUA. Esta situação afetou o Oceano Atlântico Norte, onde causou sucessivas tempestades que assolaram Portugal, provocando diversos estragos no litoral. Uma das tempestades mais intensas, 
que originou diversas storm waves (ondas de tempestade) no litoral Português, foi a tempestade Hércules, que ocorreu entre o período de 5 a 7 de Janeiro de 2014 (Antunes, 2014).

\section{Enquadramento}

Nas últimas décadas, inúmeras investigaçôes têm sido realizadas na identificação de depósitos induzidos por tsunamis de forma a identificar as suas fontes sedimentares e avaliar os impactos naturais associados. Contudo, apesar de os depósitos induzidos por tsunamis recentes estarem bem descritos historicamente, a identificaçáo de depósitos induzidos por paleotsunamis é mais controversa, pois as evidências geológicas podem ser provenientes de outros eventos de grande energia, como por exemplo as ondas de tempestade (Font et al. 2013).

Nos últimos anos, têm sido realizadas diversas investigaçóes de forma a tentar distinguir um depósito induzido por um tsunami, de um induzido por uma onda de tempestade. Contudo, continuam a existir poucos estudos para investigar diretamente a diferença entre estes dois depósitos de alta energia (Kortekaas e Dawson, 2007). Um exemplo destes estudos, foi a investigação de Tuttle et al. (2004) que comparou o tsunami Grand Banks que ocorreu em 1929 na Terra Nova (Newfoundland, América do Norte) com a tempestade Halloween que ocorreu em 1991 no Massachusetts (América do Norte). Estes autores mostraram diferenças na sedimentologia e posição dos dois depósitos, afirmando que o depósito de tsunami consiste numa de três subunidades de areia classificada, enquanto que o depósito de tempestade apresenta laminação e uma estratificação planar com canais. No mesmo seguimento de comparação de depósitos, Goff et al. (2004) compararam um depósito de tempestade recente com um depósito de tsunami do século XV no mesmo local da Nova Zelândia, tendo desta forma descoberto que ambos os depósitos diferem na extensão horizontal, e nas características de espessura e tamanho do grão. Da mesma forma, no Martinhal - Algarve, Kortekaas e Dawson (2007) mostraram que existe um determinado número de diferenças entre um depósito de tsunami 
e um depósito de tempestade, pois os depósitos de tsunami contêm burgaus e seixos que por vezes apresentam perfurações de moluscos na sua superfície. Adicionalmente, afirmam ainda que o depósito de tsunami apresenta maior concentração de foraminíferos do que o depósito de tempestade, apresentando no entanto ambos características similares de tamanho de grão. Contudo, a maioria das características indicam alto valor energético ou uma origem marinha do depósito, portanto estes dois tipos de depósitos muitas vezes apresentam características similares como se pode visualizar na TABELA I.

TABELA I - Diferentes características entre depósitos de tsunami e depósitos de tempestade. Adaptado de Kortekaas, 2002.

TABLE I - Different characteristics found in tsunami and storm deposits. Adapted from Kortekaas, 2002.

\begin{tabular}{|c|c|c|}
\hline Evidence & Tsunami Deposits & Storm Deposits \\
\hline Morphological & - Washover fans behind breached barriers & - Washover fans behind breached barriers \\
\hline \multirow[t]{4}{*}{ Stratigraphical } & - Thins indland and becomes discontinous & - Thins inland \\
\hline & - Fines inland & - Fines inland \\
\hline & - Erosional basal contact & - Erosinal basal contact \\
\hline & - Large inland extent & - Relative smaller inland extent \\
\hline \multirow[t]{7}{*}{ Sedimentological } & - Boulders & - Boulder deposition has been reported \\
\hline & $\begin{array}{l}\text { - One or more fining upward sequenc- } \\
\text { es, sometimes homogeneous }\end{array}$ & - Fining upward or homogeneous \\
\hline & - Intraclasts from underlying material & - Not found \\
\hline & - Loading structures at base & - Not found \\
\hline & - Bi-directional imbrication & - Unidirectional imbrication \\
\hline & $\begin{array}{l}\text { - Poorly sorted (particle size ranging } \\
\text { from mud to boulders) }\end{array}$ & - Relatively better sorted \\
\hline & $\begin{array}{l}\text { - Sedimentary structures very seldom } \\
\text { found }\end{array}$ & - Sedimentary structures more common \\
\hline Geochemical & $\begin{array}{l}\text { - Increase in geochemical elements indi- } \\
\text { cating marine origin }\end{array}$ & $\begin{array}{l}\text { - No information found, but similar sig- } \\
\text { nature is expected because of marine } \\
\text { origin }\end{array}$ \\
\hline \multirow[t]{7}{*}{ Paleontological } & - Marine fóssil & - Marine fóssil \\
\hline & $\begin{array}{l}\text { - Increased diversity (mixture marine } \\
\text { and brackfish fossils) }\end{array}$ & $\begin{array}{l}\text { - Mixture of marine and fresh water } \\
\text { fóssil }\end{array}$ \\
\hline & - Relative well/poorly preserved fóssil & - Poorly preserved fóssil \\
\hline & - Plant fragments & - Plants fragments \\
\hline & - Shell rich units & - Shell fragments \\
\hline & - Rafting light material & - Not found \\
\hline & - Buried plants at base & - Buried plants at base \\
\hline
\end{tabular}


Estes estudos utilizaram várias ferramentas geológicas, geofísicas e geoquímicas para fazer a distinçấo entre um depósito de tempestade e um depósito de tsunami. As ferramentas sedimentológicas (Análise Granulométrica), micropaleontológicas, macropaleontológicas e geomorfológicas são as mais tradicionais para este tipo de estudo (Goff et al., 2012). As abordagens geoquímicas são as menos exploradas, apesar das análises aos sedimentos provenientes de ambientes costeiros e lagunares já terem sido utilizadas com sucesso como indicador de inundaçôes provocadas por um tsunami (Andrade et al., 2003). As análises magnéticas (por exemplo: Anisotropia de Suscetibilidade Magnética; Andrade et al., 2003; Font et al., 2010) e as análises de colorimetria (Simóes, 2012; Font et al., 2013) foram, recentemente, de igual forma aplicadas a depósitos de tsunamis, contudo estes métodos precisam de ser expandidos e calibrados mundialmente. A identificação dos depósitos induzidos por tsunamis não é ainda muito concreta, pois estes depósitos dependem essencialmente do seu local de deposição e da fonte sedimentar, sendo estes fatores importantes para relacionar os depósitos com o meio ambiente e as geomorfologias circundantes.

\section{Área de Estudo}

Tal como referido anteriormente, o depósito de tsunami gerado pelo terramoto de Lisboa de 1755, alvo de estudo no presente trabalho, encontra-se devidamente identificado no Estuário da Boca do Rio, no Algarve, a Sul de Portugal, tendo sido já alvo de estudo e de reconhecimento prévio (fig. 1), (Font et al., 2010; Simôes, 2012; Font et al., 2012; Font et al., 2013). Estes reconhecimentos indicaram que as observaçôes realizadas no testemunho sedimentar BR-5 (T4 - fig. 1) permitiram a identificação de três camadas principais (A, B e C). As camadas A e C são lodosas e enquadram as areias da camada B. Estas duas camadas, para além de serem lodosas, contêm ainda restos de plantas, ou seja, são muito monótonas em relaçấo à sua textura. Adicionalmente, apresentam 
também um elevado teor em matéria orgânica, sugerindo que essas camadas pertencem a ambientes de deposiçáo de baixa energia, de pouco contato com ondas, ocasionalmente de águas estagnadas e com pouca profundidade (Costa et al., 2005, fig. 1). A camada B, identificada como depósito de tsunami, é uma unidade constituída essencialmente por areias bioclásticas, por vezes finas. $\mathrm{Na}$ base desta camada estão burgaus, seixos e mesmo blocos calcários. No topo, apresenta uma ou duas sequências sedimentares arenosas com diminuiçáo da dimensão das partículas na direção do topo, e sempre com a presença de restos de conchas de bivalves marinhos (fig. 1). Na análise granulométrica, os autores utilizaram três parâmetros de análise (média do tamanho do grão $(\mu \mathrm{m})$, calibraçấo da amostra $(\mu \mathrm{m})$, classificação do grâo $(\mu \mathrm{m}))$ e nos três tipos de amostra (a Amostra Total onde a análise é realizada à totalidade da amostra; a Amostra Mineral onde a matéria orgânica é removida do sedimento com o Peróxido de Hidrogénio $\left(\mathrm{H}_{2} \mathrm{O}_{2}\right)$; a Amostra Siliciclástica onde são removidos os carbonatos com ácido clorídrico (HCL) a 10\%.), a unidade A e C têm características similares (Fine Silt - Silte Fino ou Medium Silt - Silte Médio), enquanto a unidade B, identificada como depósito de tsunami, é representada por vários picos, atingindo classes granulométricas maiores, como Silte Grosseiro - Coarse Silt e Silte Muito Grosseiro - Very Coarse Silt, indicando assim a presença de uma maior percentagem de grãos de maior dimensão na amostra.

Este registo sedimentológico está presente no Estuário da Boca do Rio, uma área que apresenta baixa energia (Ondulaçáo (Altura Média): $1 \mathrm{~m}$ ) e uma costa mesotidal $(3.4 \mathrm{~m}-3.5 \mathrm{~m})$, sendo ainda um caso próprio de enseada de praia (Extensão da frente de praia; $\sim 138 \mathrm{~m}$ ), que interrompe um troço costeiro rochoso calcário, de forma erosiva e essencialmente modelado em arribas vivas (APA, 2011). Esta interrupção é composta por um vale, que possui uma forma aplanada e quase horizontal (muito diferente das secções em "V") resultante do intenso e continuo preenchimento por parte de aluvióes, depositados na existência de cheias efémeras (fig. 1). Neste vale, são recebidas drenagens de terrenos de natureza calcária com uma grande quantidade de carga sólida e lodosa, de proveniência continental, ao contrário do aporte de areias, que é diminuto (Costa et al., 2005). 
Aproximadamente a $1 \mathrm{~km}$ da linha de costa, a ribeira que está incorporada no vale e desagua no mar junto ao seu limite nascente, numa diminuta praia de areia e cascalho, divide-se em 3 afluentes com dimensōes diferentes: a Ribeira de Budens, a Ribeira de Boi e a Ribeira de Vale Barão (Costa et al., 2005). Esta pequena e estreita praia apresenta uma orientação OSO-ENE, estando diretamente exposta às ondas de Sudeste. No entanto, a sua reduzida saliência em direçáo ao mar permite às ondas de Sudoeste também terem impacto na praia. Adicionalmente, esta praia é, ainda, composta por areia média que está sobreposta a burgaus, em que estão separadas da terra por um storm ridge no centro e por um erosional bluff a oeste (Carrasco et al., 2007).

Tal como apontado por Font et al., (2010), sendo este vale nivelado a uma cota que excede o máximo de preia-mar de marés vivas, e onde as ondas de tempestade não o ultrapassam, proporciona assim excelentes condiçôes (características morfológicas e sedimentares) para preservar registos sedimentológicos do tsunami de 1755 .
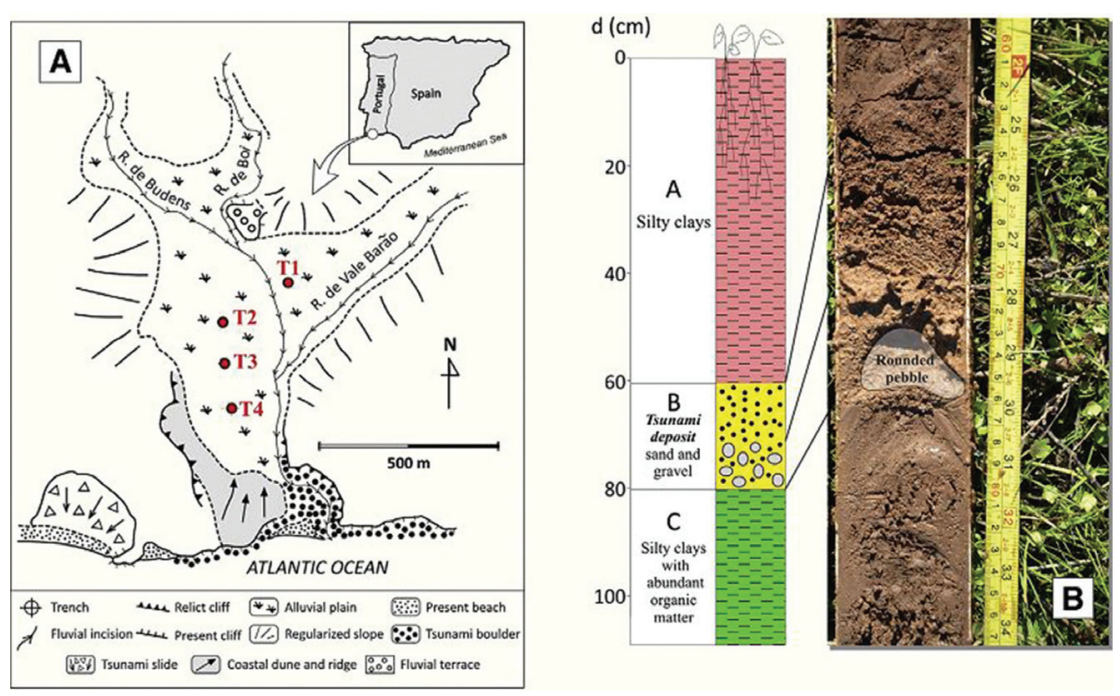

Fig. 1 - A) Mapa geológico e estrutural da Boca do Rio (Fonte: Font et al., 2013).

B) Fotografia e descrição do testemunho sedimentar do Trench 4 (T4) - BR-5.

Fig. 1 - A) Geologic and Structural Map at the Boca do Rio (Source: Font et al., 2013). $B$ ) Description of gutter sampled in Trench $4-B R-5$. 
Tempestades e Agitação marítima no Inverno de 2013-2014 que tiveram impacto na área de estudo

A forte agitação marítima que atinge a costa portuguesa é na sua maioria gerada por tempestades extratropicais que se formam no Atlântico Norte e se desenvolvem de Oeste para Este. No núcleo destas tempestades, existem ventos persistentes e concentrados que formam largas áreas de atrito entre o mar e a atmosfera, aumentando assim os valores de geração de ondas de swell (Antunes, 2014). Na costa portuguesa, entre Dezembro de 2013 e Março de 2014, existiu um fenómeno, aparentemente novo, caracterizado por uma intensa e persistente agitação marítima que originou galgamentos e causou danos costeiros consideráveis. No entanto, este tipo de agitação, que atingiu a costa portuguesa, encontra-se dentro dos parâmetros habituais (Ondas Significativas: 9- 12 m; Períodos: 14 - 16 s; Picos Máximos: chegaram aos 15 m: Marégrafo de Cascais e de Lagos. Antunes, 2014). Contudo, a quantidade de eventos desta natureza que se repetiram em menos de 3 meses, e a frequência com que ocorreram, é que está fora do habitual. Um exemplo destes eventos foi a tempestade Hércules, que ocorreu a 6 de Janeiro de 2014, sendo que durante este evento registaram-se períodos de ondas na ordem dos 22 segundos, o que constituiu também um evento atípico. Esta tempestade causou diversos danos costeiros e foram registados galgamentos que não são comuns para esta altura significativa de ondas (Antunes, 2014).

\section{Metodologia}

Após um breve enquadramento relativamente à identificação de depósitos de tsunamis e às tempestades que assolaram Portugal entre Dezembro de 2013 e Março de 2014, é então explicada a metodologia utilizada neste trabalho. Como referido anteriormente, o período de inverno em causa registou uma persistência atípica de tempestades e, por consequência, uma persistente agitação marítima. De modo a registar esta persistência no Estuário da Boca do Rio, e de forma a 
ser possível comparar um depósito associado a uma onda de tempestade - storm waves com um depósito de tsunami, realizou-se uma campanha observacional durante a tempestade Hércules no dia 6 de Janeiro de 2014, e outra após a tempestade no dia 11 de Janeiro de 2014.

$\mathrm{Na}$ campanha durante a tempestade, apenas se realizaram observações e registos dos limites de espraio. Na campanha após a tempestade, identificaram-se estes limites e os sedimentos transportados por parte desta movimentação. Desta forma, com auxílio de um dispositivo GPS, de uma espátula e de sacos de amostragem, recolheram-se amostras destes sedimentos (BRCH-3) e obtiveram-se as coordenadas dos limites. Paralelamente, também se recolheram amostras superfíciais (BRCH-1 e BRCH-2) na zona alagada por água doce e também se identificaram os limites desta zona inundada. Assim sendo, e através destes limites, criaram-se dois modelos, um modelo tridimensional e um modelo conceptual da área de estudo com a representação das áreas de sedimentação dos diferentes fenómenos associados. Por fim, foram recolhidos vários testemunhos locais para fundamentar algumas conclusões.

Para comparar as amostras superficiais (BRCH-1, BRCH-2, BRCH-3) com o testemunho do depósito de tsunami (BR-5), analisaram-se estas amostras ao nível da granulometria. Nestas análises, utilizaram-se as mesmas técnicas que foram utilizadas para analisar o testemunho BR-5, nomeadamente a utilização do granulómetro laser Malvern ${ }^{\mathrm{TM}}$, no qual se utilizou o programa Malvern MasterSizer ${ }^{\mathrm{TM}}$ para a obtenção dos resultados. Os dados obtidos através desta análise foram então exportados para o Excel e introduzidos no GRADISTAT $^{(}$ (Blott, 2010) para calcular os diversos parâmetros granulométricos (Média, Classificação e Calibração do grão $(\mu \mathrm{m})$ ). De referir, ainda, que estas técnicas foram apenas aplicadas às amostras totais. 


\section{Resultados e Discussão}

\section{Observação da tempestade e da sua influência na área de estudo}

Através das observaçóes realizadas durante a campanha observacional, aquando da tempestade em causa, verificou-se que o máximo que a água do mar atingiu (Espraio) foi a localização de BRCH-3 (Lon: -8.80 Lat: 37.06º), permitindo, desta forma, definir a zona que foi alvo da água do mar (fot. 1). O facto desta enseada de praia ter presente uma pequena ribeira que desemboca no mar, permitiu que as ondas produzidas durante esta tempestade provocassem o bloqueio desta ribeira através do transporte de areias. Assim sendo, este bloqueio permitiu o acumular de areias na zona circundante à ribeira, sendo que à medida que nos afastamos da mesma (E para $\mathrm{O})$ a quantidade de areia passa a ser mínima. Para além da areia e dos vestígios de areia que o bloqueio da ribeira provocou na zona que foi afetada pela água do mar, este bloqueio também provocou uma inundação de água doce a norte do limite afetado pela água do mar. No entanto, esta zona foi alagada (assinalada a amarelo na fot. 1) com água oriunda de escorrências das vertentes e de precipitação, o que provocou uma inundação de água doce até à localização de BRCH-2 (Lon: $-8.81^{\circ}$; Lat: $37.06^{\circ}$ ) e BRCH-1 (Lon: $-8.81^{\circ}$; Lat: $37.07^{\circ}$ ). Nesta área que se encontrava alagada por água doce, não existia vestígios de areia e o sedimento da superfície era idêntico ao topo do testemunho BR-5. Este registo observacional está presente na fot. 1 e na fig. 2.

Portanto, e através destas observaçóes, é possível afirmar que durante esta tempestade ocorreu um evento de inundação, pois a água do mar atingiu o primeiro limite de praia mas já não teve força suficiente para depositar e atingir a zona amarela, o que descarta um possível overwash. Adicionalmente, o facto de a ribeira ficar bloqueada permitiu a ocorrência de uma inundação e de uma deposição sedimentar na zona próxima da ribeira (zona vermelha na fot. 1) e, ainda, permitiu que a zona a amarelo (fot. 1) ficasse alagada por água doce proveniente de escorrências das vertentes e precipitação. 
Modelo tridimensional da área de estudo e representaçáo das áreas de sedimentação dos diferentes fenómenos analisados

De forma a representar espacialmente a área de estudo, juntamente com as áreas de sedimentação dos diferentes fenómenos analisados, foram elaborados dois modelos, um tridimensional e um modelo conceptual. Na fig. 2 está presente um modelo digital de terreno da área de estudo com o intuito de auxiliar as interpretaçôes das áreas de sedimentação. Neste modelo, pode-se verificar a forma aplanada ( 1 a $2 \mathrm{~m}$ de altitude) onde está presente o depósito de tsunami e que está incluído no vale que interrompe o troço costeiro rochoso calcário. Adicionalmente, é ainda possível verificar que existe um limite mais elevado entre a praia e esta forma aplanada ( 4 a $10 \mathrm{~m}$ ), sendo que na zona da ribeira (Este) esta zona elevada não existe ou é mínima devido à existência da ribeira ( 1 a 2 m). Portanto, este limite mais elevado é o que não deixa que a água do mar inunde e chegue à planície (forma aplanada). Por outro lado, as baixas elevaçôes na zona da ribeira permitiram inundaçôes nesse local.

Como este modelo não apresenta uma resolução espacial que permita uma análise detalhada, criou-se um modelo conceptual da área de estudo com as

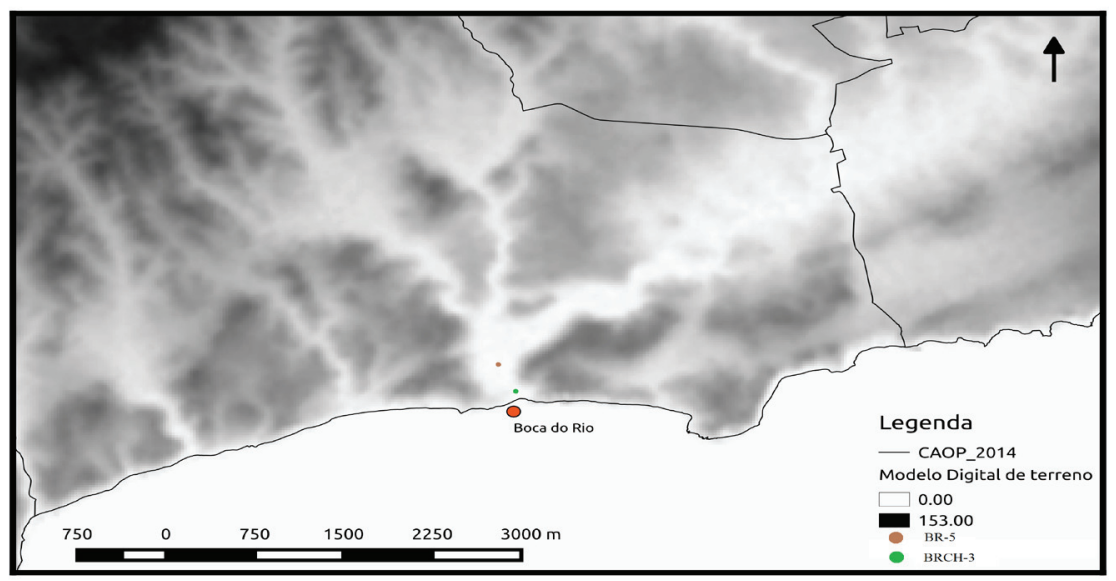

Fig. 2 - Modelo Digital de Terreno da área de estudo. Fonte: SRTM com resolução espacial de $25 \mathrm{~m}$.

Fig. 2 - Terrain Digital Model from study area. Source: SRTM, spacial resolution $25 \mathrm{~m}$. 
áreas de sedimentação dos diferentes fenómenos analisados (fot. 1). Este modelo conceptual foi criado através de uma fotografia panorâmica da área de estudo, pois permite uma melhor visualização e análise destas áreas. Desta forma, delimitou-se a zona que a água do mar atingiu por zona vermelha, sendo que, a zona que foi mais afetada por esta inundação e por acumulação sedimentar foi a região mais próxima da ribeira (Este). Por outro lado, delimitou-se a zona alagada por água doce e que contém o depósito de tsunami, mas que não foi afetada pela água do mar. Como referido anteriormente, a zona a amarelo apenas foi inundada devido ao bloqueio da ribeira, que por sua vez fez com que a precipitaçấo e as escorrências das vertentes a fizessem alagar.

Para completar esta interpretaçấo das zonas afetadas pela tempestade, compararam-se alguns modelos de inundação aplicados a esta área de estudo por outros autores, com o limite máximo de inundação gerado pelas storm waves. Segundo os modelos de inundação AnuGA e COMCOT (Fernandes, 2009) e, ainda, pela simulação numérica de Font et al., (2010), verificou-se que o tsunami de 1755 foi suficientemente forte para ultrapassar a duna litoral de areia, erodir e afetar consideravelmente a morfologia do Estuário da Boca do Rio, no qual depositou sedimentos até, aproximadamente, $1 \mathrm{~km}$ no interior e com um máximo de run up de $7 \mathrm{~m}$, com inundaçóes de profundidade entre 0,5-6m e velocidades de corrente $2-7 \mathrm{~m} / \mathrm{s}$ (fig. 4). Ilustradamente, compararam-se estes

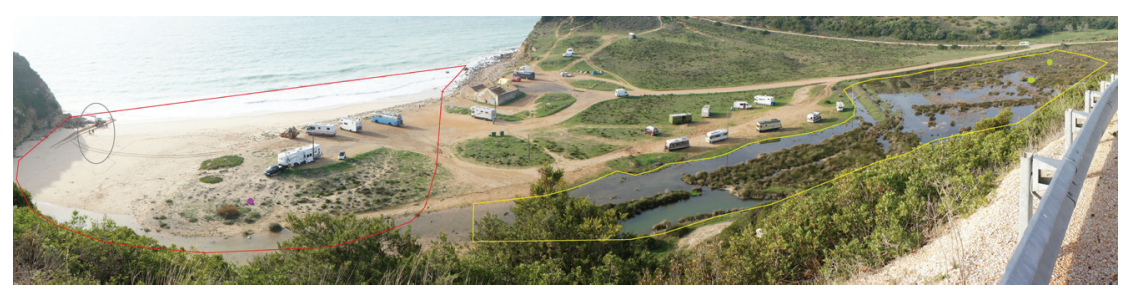

Foto. 1 - Efeitos da tempestade no Estuário da Boca do Rio. Vermelho: Zona de inundação da água do mar; Amarelo: Zona alagada com água doce; Cinzento: Retroescavadora a abrir a ligação da ribeira ao mar; Roxo: Amostra BRCH-1; Verde:

Amostra a sul é BRCH-2 e a Amostra a norte é BRCH-3.

Photo 1 - Effects of storm at the Boca do Rio. Red: Flooding zone of seawater; Yellow: Flooded area with fresh water; Gray: Backhoe to open the connection of the riverside to the sea; Purple: Sample BRCH-1; Green: BRCH-2 (South) and BRCH-3 (North). 
modelos de inundação com o limite máximo de inundação gerado pelas storm waves provenientes da tempestade Hércules, observadas e registadas durante a campanha observacional. Desta forma, e através da fig. 3, verifica-se que uma storm wave, com as características registadas durante esta tempestade, não tem capacidade para criar um depósito como o registado no testemunho BR-5 (localização e morfologia), pois esta onda de tempestade apenas transportou sedimento fino até ao limite assinalado a verde na fot. 1 .

\section{Observação direta às amostras recolhidas}

As amostras (BRCH-1 e BRCH-2) recolhidas na zona alagada por água doce apresentam as mesmas características que o topo do testemunho BR-5 (Camada A). Isto é, são amostras lodosas, contêm restos de plantas, apresentam elevado

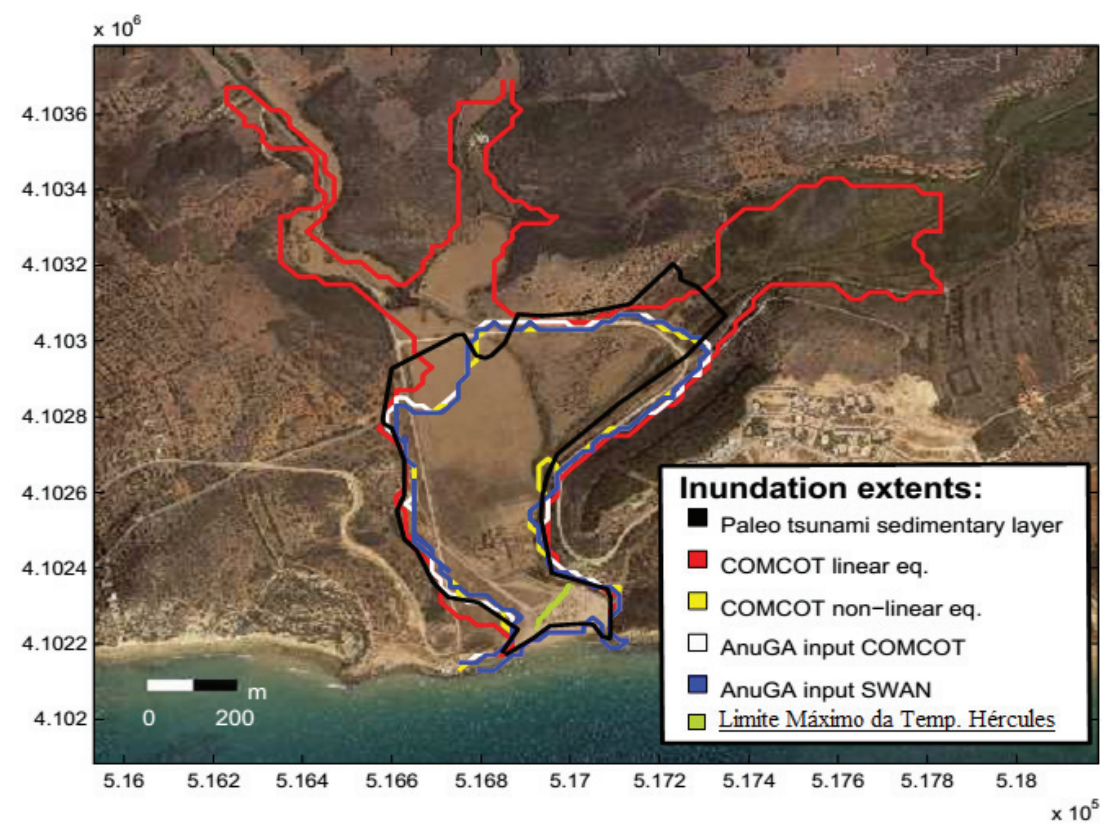

Fig. 3 - Modelos de inundação do tsunami de 1755 em comparação com o limite máximo que a água do mar atingiu (Adaptado de: Fernandes, 2009).

Fig. 3 - Inundation models of 1755 tsunami in comparison with maximum limit that water reached (Adapted from: Fernandes, 2009). 
teor em matéria orgânica (o que sugere que estas amostras pertencem a um ambiente de deposição de baixa energia). Detêm pouco contacto com ondas e, ocasionalmente, são de águas estagnadas, de baixa profundidade e anóxicas (Costa et al., 2005). A amostra (BRCH-3), recolhida na zona de espraio ao contrário do depósito de tsunami do testemunho BR-5 (Camada B), apenas apresenta uma estrutura laminar constituída por areias bioclásticas finas. Esta constituição deve-se ao facto de a camada $\mathrm{B}$, para além destas areias, ser na sua base composta por burgaus, seixos e mesmo blocos calcários, sendo que o tamanho das partículas diminuem na direção do topo. Adicionalmente, esta camada B também é composta por restos de conchas e bivalves marinhos (Costa et al., 2005). Por fim, é ainda importante referir que a espessura das amostras recolhidas durante a campanha observacional não eram suficientemente espessas para se poder observar alguma estrutura vertical.

\section{Análise granulométrica}

Realizaram-se análises de granulometria (média do tamanho do grão, calibração da amostra e classificação do grão) às amostras recolhidas durante a tempestade Hércules. Os resultados foram representadas graficamente em conjunto com os resultados do testemunho BR-5, de forma a compará-las com o depósito de tsunami (fig. 4).

Através da fig. 4, e tal como Simóes (2012) e Font et al. (2013) identificaram, no testemunho BR-5 as camadas A e C apresentam características muito similares (Silte Fino e Silte Médio), enquanto que, por outro lado, a camada B (Depósito de tsunami) é representada por vários picos, atingindo classes granulométricas superiores (Silte Grosseiro e Silte Muito Grosseiro). De referir ainda que o pico na profundidade $34 \mathrm{~cm}$ é considerado como um erro de análise, uma vez que não se observa a olho nu nenhuma variação associada no testemunho.

As amostras BRCH-1 e BRCH-2, recolhidas na zona alagada por água doce, apresentam características idênticas (Silte Fino e Silte Médio, respetivamente) 
ao topo do testemunho BR-5. Já a amostra BRCH-3, que foi recolhida na zona de espraio, atingiu classes granulométricas superiores comparativamente a todas as outras (Areia Siltosa).

Desta forma, torna-se então possível afirmar que as amostras recolhidas na zona alagada por água doce, a nível de granulometria, são similares ao topo do testemunho BR-5. Assim sendo, a zona alagada não foi atingida por areias transportadas pela storm wave da tempestade Hércules. Relativamente à amostra

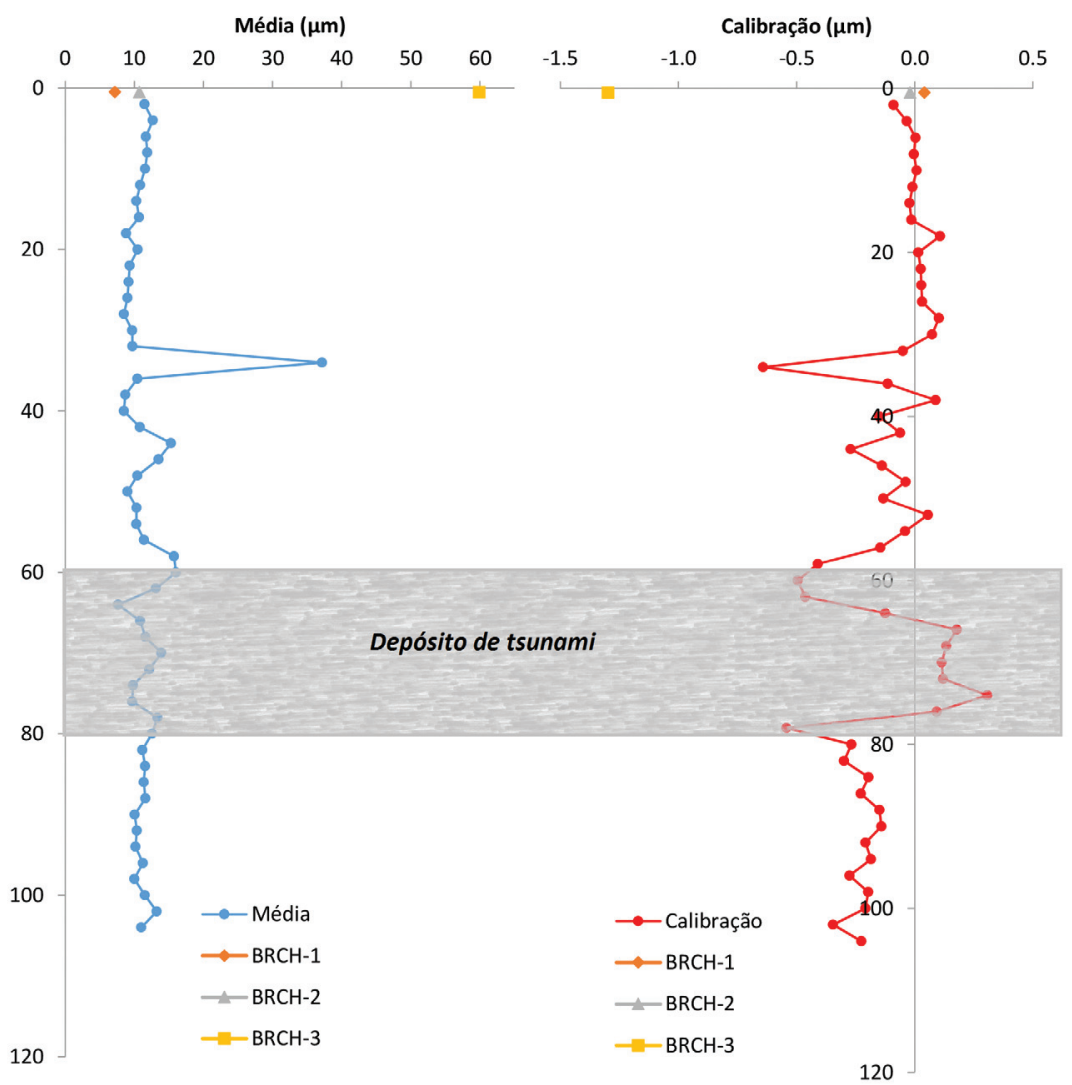

Fig. 4 - Média e Calibração do grão $(\mathrm{em} \mu \mathrm{m})$ do testemunho BR-5 e das amostras BRCH-1, BRCH-2 e BRCH-3.

Fig. 4 - Grain mean and Sorting (in $\mu m$ ) of BR-5 sediment core and BRCH-1, BRCH-2 and $B R C H-3$ samples. 
TABELA II - Classificação do grão (\%).

TABLE II - Grain Classification (in \%).

\begin{tabular}{|l|c|c|}
\hline & \% Areia & \% Lama: \\
\hline BRCH-1 & $7.8 \%$ & $92.2 \%$ \\
\hline BRCH-2 & $16.2 \%$ & $83.8 \%$ \\
\hline BRCH-3 & $69.8 \%$ & $30.2 \%$ \\
\hline
\end{tabular}

BRCH-3, como a mesma apresentou classes granulométricas superiores (Areia Siltosa), pode-se então afirmar que a energia das ondas que transportou estas areias foi elevada.

Com esta análise granulométrica pode-se afirmar que a tempestade Hércules não teve capacidade para atingir a zona alagada, pois esta zona não sofreu input de areias durante a tempestade. Por outo lado, a zona que a água do mar atingiu foi alvo de transporte de areias.

Adicionalmente, é ainda possível afirmar que o depósito de tsunami é induzido por uma onda suficientemente forte para erodir quantidades importantes de areias e compostos marinhos da duna litoral, onde estes materiais são retrabalhados e misturados entre si e com materiais que encontram durante o seu percurso. Este fenómeno deve-se ao facto das ondas de tsunami apresentarem um período bastante longo, permitindo a tal mistura. Esta mistura é constituída maioritariamente por material autóctone, isto é proveniente da própria praia e do próprio estuário (Font et al., 2013). Por outro lado, esta storm wave (Hércules) contém um período bastante menor do que o de uma onda de tsunami, ou seja, estas ondas de tempestade apenas transportam e depositam os materiais que a sua força permite (nesta situação: areias siltosas). Assim, esta storm wave não teve intensidade nem período suficientemente elevados para criar um depósito de tipo tsunami como o identificado em BR-5, ou seja, um depósito com uma grande mistura de materiais. 


\section{Conclusão}

Através das observaçóes realizadas aquando da tempestade é possível afirmar que ocorreu um evento de inundaçáo, pois a água do mar atingiu o primeiro limite de praia mas já não teve força suficiente para depositar e atingir a zona alagada por água doce, o que descarta um possível overwash. Assim sendo, foi o facto da ribeira ficar bloqueada que permitiu a ocorrência de uma inundação e de uma deposição sedimentar na zona próxima da ribeira (zona vermelha na Fot. 1), permitindo, ainda, que a zona a amarelo (fot. 1) ficasse alagada por água doce proveniente de escorrências das vertentes e precipitaçáo.

Adicionalmente, procedeu-se a uma comparaçáo entre os modelos de inundação AnuGA e COMCOT (Fernandes, 2009), e, ainda, entre os modelos de inundação testados por Font $e t$ al. (2010), com o limite máximo de inundação das storm waves oriundas da tempestade Hércules (5 a 7 de Janeiro de 2014), tendo-se verificado que ondas de tempestade com as características idênticas às geradas por estas tempestades náo têm capacidade para gerar um depósito como o identificado no testemunho BR-5.

No que respeita às amostras recolhidas durante a campanha observacional, as mesmas permitem identificar diversas diferenças entre o depósito de tsunami e os materiais transportados pelas ondas de tempestade. A nível observacional, as amostras BRCH-1 e BRCH-2 apresentam características similares comparativamente ao topo do testemunho BR-5, enquanto que a amostra BRCH-3 apresenta na sua maioria areias. Estas diferenças nas análises granulométricas também foram identificadas. Relativamente às amostras BRCH-1 e BRCH-2, estas também apresentam as mesmas classes granulométricas (Silte Fino e Silte Médio, respetivamente) que o topo de BR-5, enquanto que a amostra BRCH-3 apresenta classes granulométricas superiores (Areia Siltosa) às do testemunho BR-5 na sua totalidade, o que indica que a onda que transportou estes sedimentos tinha elevada energia. Desta forma, e através das comparaçóes das análises granulométricas entre o testemunho BR-5 e as amostras recolhidas durante a campanha observacional, verificou-se que a storm wave em estudo não teve capacidade para transportar areias até à zona alagada, enquanto que a zona que foi atingida por água do mar foi alvo de transporte e deposição de areias. 
Por último, todos estes resultados apontam para um cenário onde a energia libertada pela onda do tsunami é suficientemente forte para erodir quantidades importantes de areia e compostos marinhos da duna litoral e, adicionalmente, para misturar e retrabalhar os materiais que encontram no seu percurso. Como a onda de tsunami apresenta um longo período, torna-se entáo possível a existência de uma grande mistura de materiais, mistura esta que é constítuida maioritariamente por material autóctone. Pelo contrário, a storm wave em estudo, como contém períodos menores que as ondas de tsunami, apenas transporta e deposita o que a sua força lhe permite (neste caso: areias siltosas). Neste caso de estudo, a storm wave da tempestade Hércules não teve intensidade nem período elevados para criar um depósito como o depósito de tsunami de BR-5, ou seja, um depósito com uma grande mistura de materiais. Perante este facto, há que também ter em consideração a influência que a batimetria e a topografia têm na deposição sedimentar.

\section{Bibliografia}

Andrade, C., Freitas, C., Miranda, J.M., Baptista, M.A., Cachão, M., Silva, P., Munhá, J., (2003). Recognizing possible tsunami sediments in the ultradissipative environment of the Tagus estuary (Portugal). Coastal Sediments '03 The fifth International Symposium on Coastal Engineering and Science of Coastal Sediment Processes, 18-23 May, Clearwater Beach, FI., ed. CD-ROM, 14 pp.

APA - AGÊNCia PORTugueSA do Ambiente (2011). Perfis de águas balneares da Boca do Rio.

Antunes, C. (2014). Eventos extremos e a variação do nível do mar. Actas das 3as Jornadas de Engenharia Hidrográfica, Instituto Hidrográfico, Lisboa 24-26 de Junho de 2014 pp. 37 - 40.

Blott, S. (2010). GRADISTAT: A Grain Size Distribution and Statistics Package for the Analysis of Unconsolidated Sediments by Sieving or Laser Granuelometry (v. 4.0).

Costa, A., Andrade, C., Seabra, C., Matias, L., Baptista, Maria. e Nunes, S. (2005). 1755 Terramoto no Algarve. Centro de Ciência Viva do Algarve. Faro

Dawson. A. G., Stewart. I. (2007). Tsunami: deposits in the geological record Sediment. Geol. 200, 166-183.

Fernandes, M. (2009). Systematic comparison on the inundation response of AnuGA and COMCOT tsunami modelling code applied to the Boca do Rio and Alvor Bay área (Tese de Mestrado em Oceanografia). Universidade do Algarve - Faro

Font, E., et al., (2010). Identification of tsunami-induced deposits using numerical modelling and rock magnetism techniques: A study case of the 1755 Lisbon tsunami in Algarve. Portugal. Phs. Earth Planet. In (2010). Doi: 10.1016/j.pepi.2010.10.006. 
Font, E., C. Veiga-Pires, F. Ruiz Muñoz, M. Pozo, M. Abad, S. Duarte, N. Simôes, S. Nave, S. Costa, L. Rebelo (2012). Testing Rock Magnetic and AMS Methods in Tsunami- and Storminduced Deposits. $13^{\text {th }}$ Castle Meeting, Zloven, poster session.

Font, E., C. Veiga-Pires, M. Pozo, S. Nave, S. Costa, F. Ruiz Muñoz, M. Abad, N. Simōes, S. Duarte, J. Rodríguez-Vidal (2013). Benchmarks and sediment source(s) of the 1755 Lisbon tsunami deposit at Boca do Rio Estuary. Marine Geology 343, pp. 1-14. Doi: /10.1016/j. margeo.2013.06.008.

Goff, J., McFaden, B.G., Chagué-Goff, C. (2004). Sedimentary differences between the 2002 Easter storm and the 15th-century Okoropunga tsunami, southeastern North Island, New Zealand. Marine Geology 204, 235-250

Goff, J., Chague-Goff, C., Nichol, S., Jaffe, B., Dominey-Howes, D., (2012). Progress in paleotsunami research. Sedimentary Geology 243, 70-88.

Kortekaas, S. 2002. Tsunamis, storms and earthquakes: distinguishing coastal flooding events. (PhDthesis)Coventry University, UK. 171p

Kortekaas, S., Dawson, A.G., (2007). Distinguishing tsunami and storm deposits: an example from Martinhal, SW Portugal. Sedimentary Geology 200, 208-221

Luque, L., Lario, J., Zazo, C., Goy, J.L., Dabrio e Silva, P.G. (2001). Tsunami deposits as paleoseismic indicators examples from the Spanish coast. Acta Geologica Hispanica v.36, pp. 197-211.

Morton, R. A., Gelfenboum, G., Jaffe, B. E. (2007). Physical criteria for distinguising sandy tsunami and sotrm deposits using modern exemples. Sediment. Geol. 200, 184-207.

Pratt, B, (2002). Storms versus tsunamis: dynamic interplay of sedimentar, diagenetic, and tectonic processes in the Cambrian of Montana. Geology 30, 423-426.

Shanmugam, G. (2006). the tsunamite problema. J. Sediment. Res 76, 718-730

Silva, A. (2009). Estudo das propriedades físicas dos sedimentos estuarinos. Relatório do trabalho decorrente da atribuição de Bolsa de Integração na Investigação. Universidade do Algarve - Faro

Simões, N. (2012). Identificação de depósitos de tsunamis de 1755, na regiâo Algarvia, seu estudo e comparação com amostras de outras regiôes. Projeto de final de licenciatura (Ciências do Mar) - Universidade do Algarve.

Tapin, R. (2007). Sedimentary features of tsunami: deposits-their origin, recognition and discrimination: on introduction. Sediment. Ged. 200, 151-154.

Tuttle, M.P., Ruffman, A., Anderson, T., Jeter, H., (2004). Distinguishing tsunami from storm deposits in eastern North America: the 1929 Grand Banks tsunami versus the 1991 Halloween storm. Seismological Research Letters 75 (1), 117-131. 